\title{
Patrimonialism in Political Economy -- A Graphic Analysis
}

\author{
Frederick Betz ${ }^{1}$ \\ ${ }^{1}$ Department of Technology and Society, SUNY Korea, Seoul, South Korea \& Department of Engineering and \\ Technology Management, Portland State University, Portland, Oregon, USA \\ Correspondence: Frederick Betz, Department of Technology and Society, SUNY Korea, Seoul, South Korea \& \\ Department of Engineering and Technology Management, Portland State University, Portland, Oregon, USA. E-mail: \\ fbetz@venture2reality.com
}

Received: June 12, 2014

Accepted: June 23, 2014

Online Published: June 25, 2014

doi:10.5430/bmr.v3n3p1

URL: http://dx.doi.org/10.5430/bmr.v3n3p1

\begin{abstract}
The purpose of the research is to continue to develop a methodological technique for abstracting empirical evidence from history about the validity of middle-range social science theories. The theory addressed here crosses the disciplines of economics, political science, sociology, and anthropology. It focuses upon middle-range theories about societal stability. The stability of a society is an important topic. From all the historical instances and studies on instability in societies, there is one generalization which stands out; and that is societies become unstable from the interactions of the systems in a society: economic, political, cultural, technological. In particular, patrimonialism (in the form of hiring kin or nepotism in an organization) is a universal problem in all governments, because the cultural system of a society has significant interactions with its political system. Societies are complicated social objects. A Weberian four-system model of a society can divide the complications into four sectors, and a further fourfold division of each sector creates a sixteen-unit functional model of a society. This model of a society can identify 120 kinds of connections between the sub-systems of a society as explanatory relations for understanding societal system stability or instability.
\end{abstract}

Keywords: Societal systems, Social stability, Political economy

\section{Introduction}

We apply a topological systems analysis to political-economic theory, in regard to the factor of 'patrimonialism' in the stability of Chinese society. We use three historical cases of Chinese society: the contemporary economic reform in the Peoples Republic of China (2014), the origin of the Chinese form of a state in the Qin Dynasty (221-206 BC), and the fall of the early Han Dynasty (206 BC - 220 AD). In all these cases, one observes 'patrimonialism' as an important relationship between government and kinship; and this has historically impacted the stability or instability of Chinese society. Patrimonialism is not unique to China, but universal in all societies in the globe and in history. These cases were chosen to study because there exist many good scholarly studies of China's ancient past, with some focusing upon 'patrimonialism'. Moreover, there are modern instances of patrimonialism which have appeared in current news about modern China. This paper casts no aspersions against the current government of China. It only examines the deep cultural aspects of any and all societies, particularly as culture interacts with political and economic systems.

The paper first reviews the methodological technique of topological modeling (graphic analysis) of society as a taxonomy of systems. The technique is applied to three historical cases about 'patrimonialism' and therein shows how a similar social pattern has occurred in both modern ancient and China. This lends empirical evidence for the validity of Francis Fukuyama's middle-range theory -- about the importance of the relationship between cultural and the political-economic systems of a society, across time.

\section{Methodology - Systems Model of Societal Stasis}

A societal systems model can be constructed, using two basic sociological dichotomies from Max Weber. (Weber, 1958) Weber had written that in any and all social interactions in a society, participants can hold four kinds of expectations about that interaction: (1) utility or identity and (2) reciprocity or authority.

By the dichotomy of utility or identity, Weber meant that in any societal interaction, each party to the interaction will anticipate either: 
(1) Utility in a relationship -- as a useful value for a participant in the interaction (such as buying or selling goods):

(2) Identity in the relationship -- as an identification of one party with the other party as belonging to some same group and sharing the values of the group (such as belonging to the same family or same political party).

By the dichotomy of reciprocity or authority, Weber meant that in any societal interaction, each party will also anticipate as a basis for the interaction either:

(1) Reciprocity in the relationship -- as a mutual and equal advantage for each party in the relationship,

(2) Authority in a the relationship -- as one of the parties in the relationship for making decisions about the relationship (such one being a judge and the other a plaintiff or one being a mayor of a city and the other a citizen).

As shown in Figure 1, a taxonomy of societal interactions has been constructed (Betz, 2001) by using the two dichotomies of expectations in social interactions: with utility-identity across the top of the matrix and reciprocity-authority down the side of the matrix.

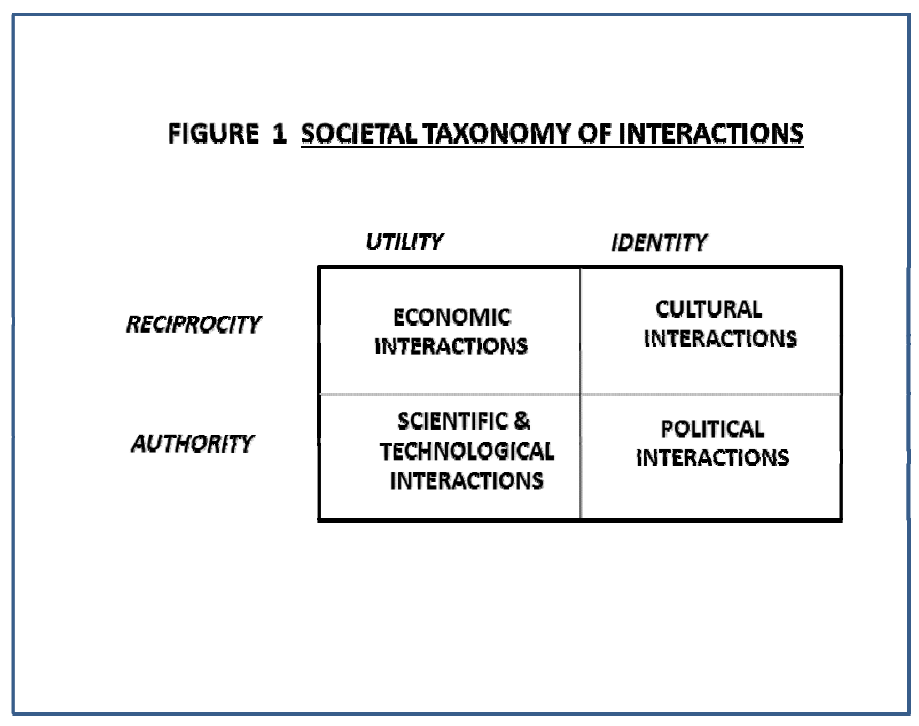

Economic Interactions are the social interactions which anticipate benefits of both utility and reciprocity. Two participants each expect from their interaction both usefulness (utility) and that utility should be fair (reciprocal) in mutual benefit. For example in an economic system, two participants in a market, as buyer and seller, expect (1) both to benefit from the sale (product for the buyer and price to the seller) and (2) that the sale should be fair (a competitive price for a quality product).

Cultural Interactions are the social interactions which anticipate benefits of both identity and reciprocity. Therein two participants each expect to share a mutual identity in their interaction and also expect actions that are reciprocal in mutual benefit (fairness). For example, two participants in a church, such as priest and congregant, both expect each to believe in the same religious faith (as members of the same church or synagogue or mosque) and share religious practice.

Political Interactions are the social interactions that anticipate benefits of both identity and authority. Therein two participants each expect to share a mutual identity in their interaction but also expect actions to be decided by the one participant superior in societal authority and performed by the inferior participant. The participant-superior-in-authority is said to hold political power over the other participant. For example, a political office-holder such as a judge in a court-of-law can sentence another participant in a trial (having been brought into court as an arrested offender) to a sacrifice of life or freedom or property. The judge has legal power over the defendant in a trial.

Science \& Technological Interactions are the social interactions that anticipate benefits of both utility and authority. Therein two participants each expect from their interaction a usefulness (utility) and also that utility is based upon an action (technical process) which can effectively create the utility -- a methodological authority which guarantees the technical effectiveness of the useful action. For example, as business person might hire an engineer to design a factory to produce the business person's product. (One example is that of a chemical engineer hired to design 
chemical processes for producing chemicals.) In this interaction, the engineer's useful action in designing a factory is based upon his methodological authority of engineering knowledge.

Next this taxonomy can be expressed as a topological graph, which each sub-system depicted as one plane stacked upon another, Figure 2.

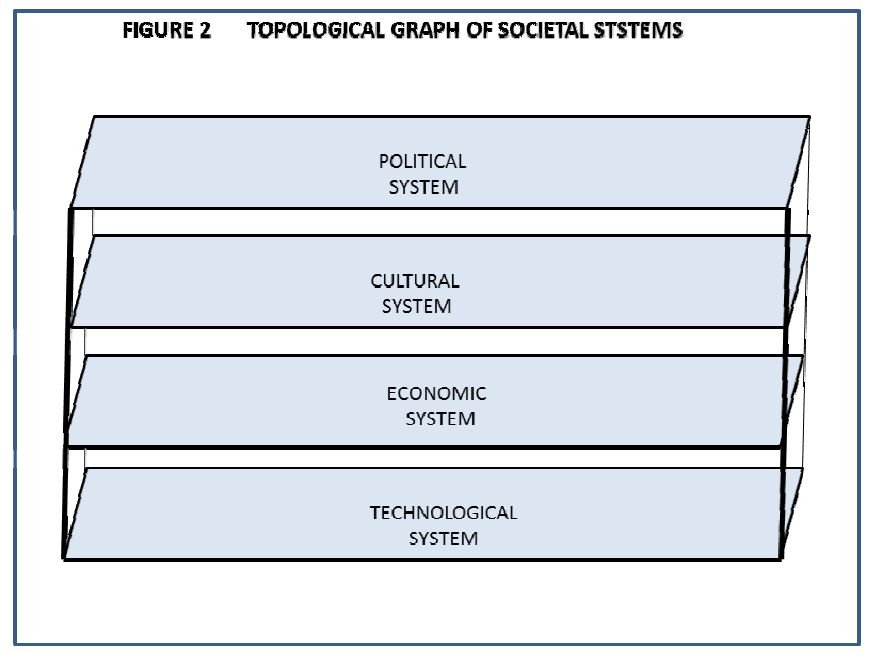

Further, one can partition each sub-system into smaller systems, as shown in Figure 3. These societal systems and their subsystems provide the functional structures of a system. The model was first developed by the author in systems dynamics theory (Betz, 2011) and later applied to the multiple explanations of the U.S. Great Depression of the 1930s (Betz, 2013)

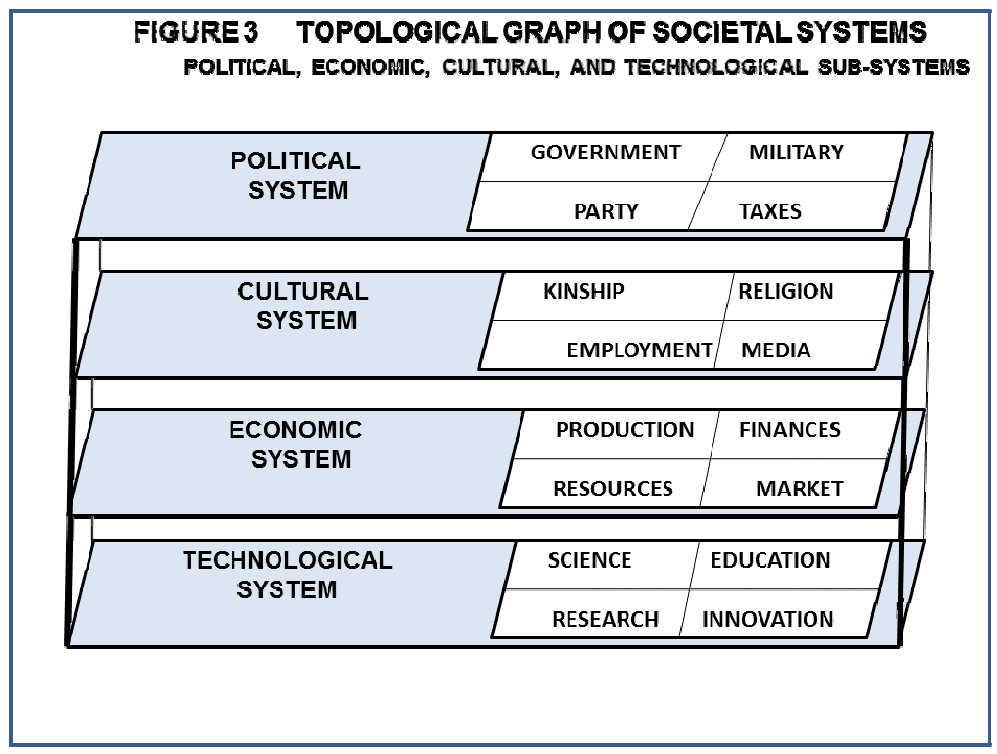

How many graphic connections can exist within and between the four sub-systems of society? One can find that there are 120 possible kinds of explanations needed to topologically model stasis connections in a societal system; and this can be most easily seen by altering the form of the topological graph of societal systems from overlapping four planes into a 'box' constructed of the four planes, as shown in Figure 4. 


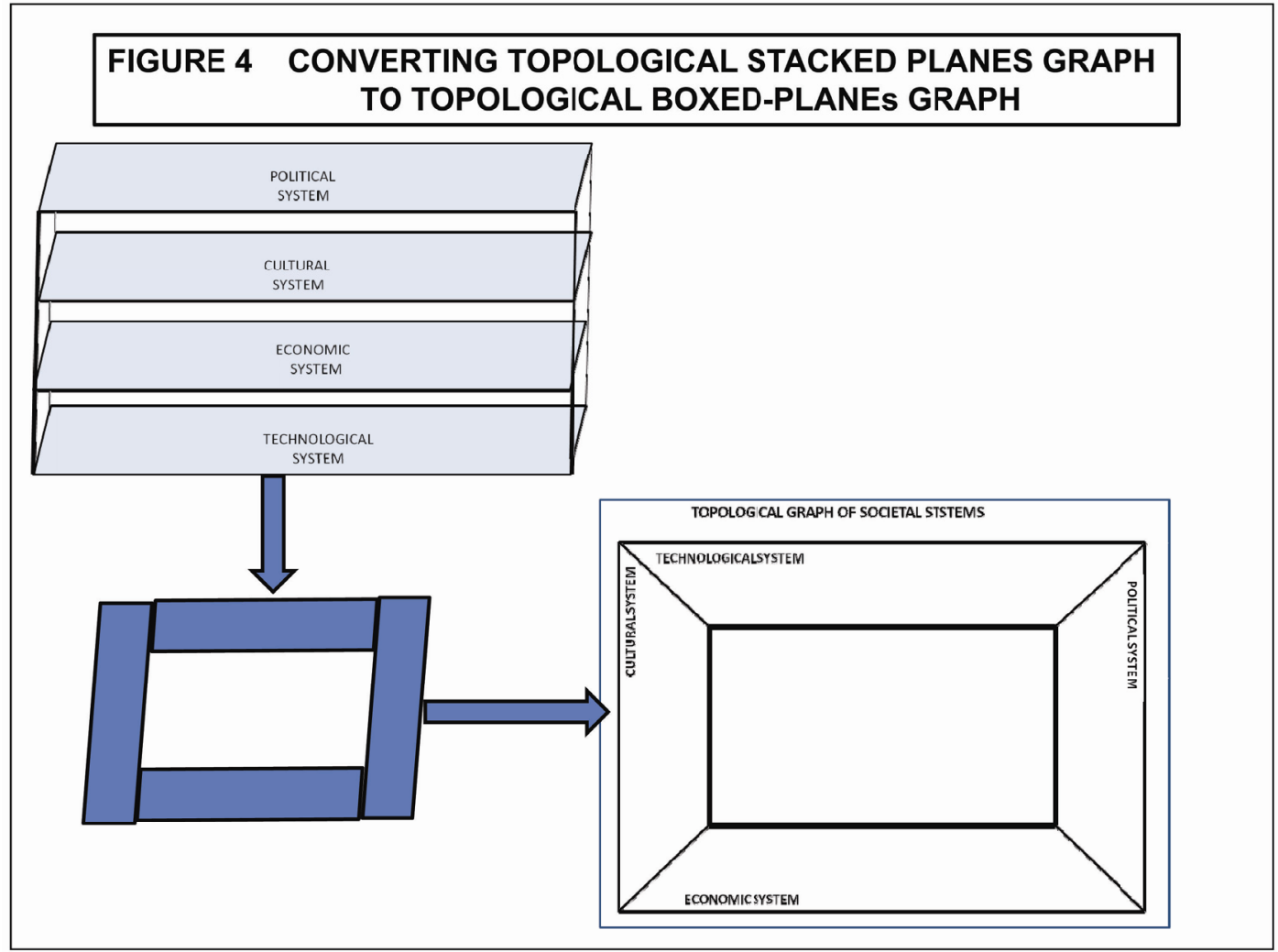

In this form, one can clearly see all the possible connections in the graphic form, as indicated by Figure 5.

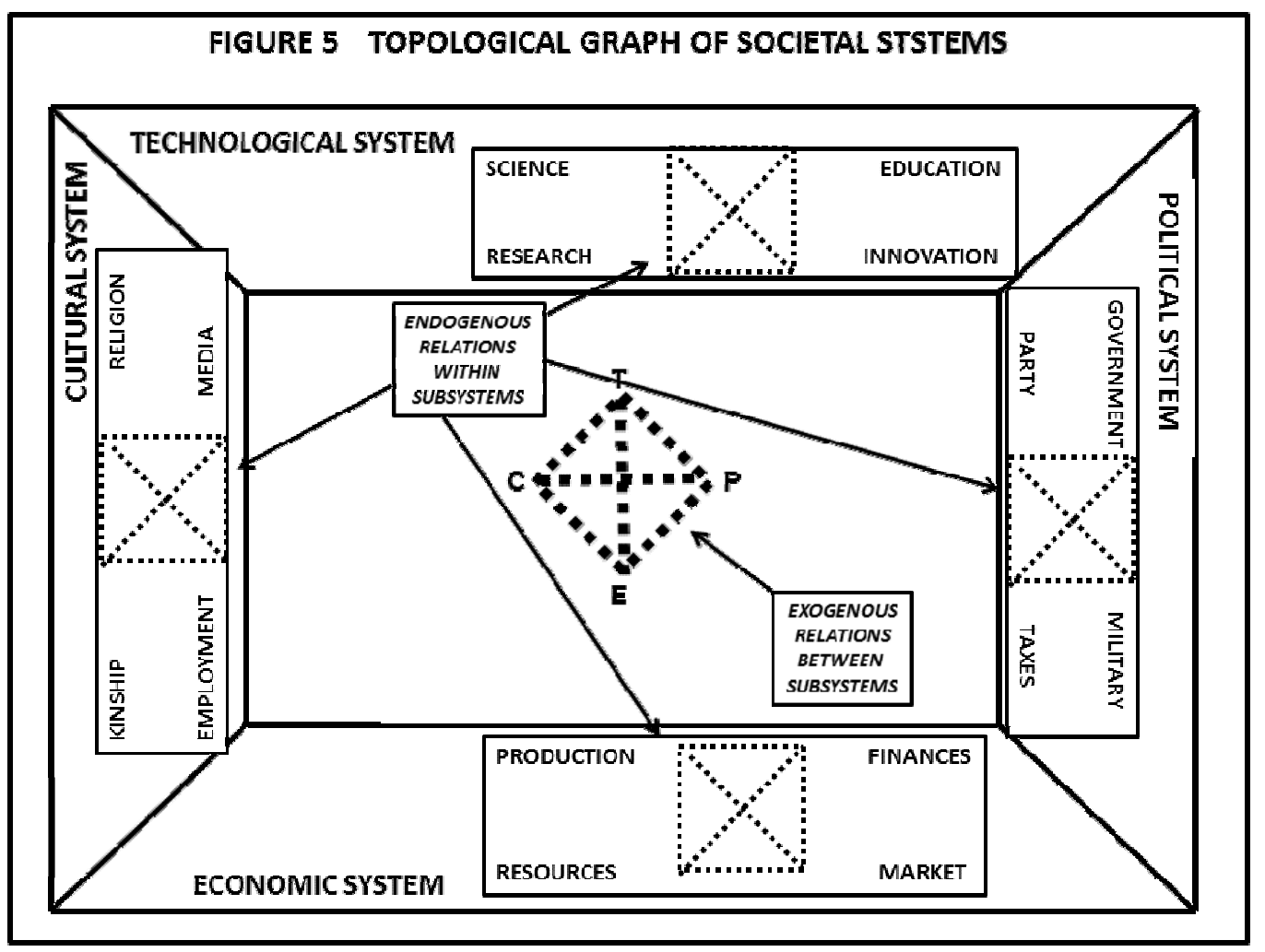

There are six connections within each of the subsystems of the four societal systems. We will call these 'endogenous relations', inside a societal system. Since there are four societal systems (technological, political, cultural, economic), there is a total of $(6 \times 4=24)$ twenty-four endogenous societal system relations. 
In addition, there are relations between the four societal systems, which we call exogenous (outside) relations. But each subsystem can connect to the other subsystems, so there are sixteen possible exogenous relations from one subsystem to another. This is true for each subsystem connecting to another subsystem, so that there are $(6 \times 16=96)$ a total of ninety-six exogenous relations.

The 24 endogenous relations added to the 96 exogenous relations $(24+96=120)$ provide a total of 120 possible relations connecting each societal system to another. This is a large number, but a finite number -- one hundred twenty ways of explaining the relations among societal systems within a society. These 120 relations are possible 'explanations' of the relationships which can occur between the different systems operating within a society.

\section{Historical Case: Patrimonialism in Reforming Modern China}

We next apply this methodology to the case of patrimonialism in contemporary China. In traditional communist dogma, Marx had called a communist state as a 'dictatorship of the proletariat'. But Lenin contributed to communist dogma by adding: a 'dictatorship by professional revolutionaries in the name of a proletariat' Mao Zedong's contribution to dogma was to have the 'dictatorship by professional revolutionaries in the name of a peasantry'. After Mao's death, Deng Xiaoping began a reform of the Chinese economy toward a 'Chinese socialism' (which encompassed capitalism), while still retaining a communist government. Thus Deng's contribution to communist theory can be seen (1) as removing 'dictatorship' as the form of a communist government and (2) replacing the ideological concept of 'class-struggle' with an idea of 'classes-cooperating-together-for-national-development'. Historically, Mao was most interested in 'class-struggle' as the dynamics of society; whereas Deng was more interested in 'national-development' for prosperity and strength.

Yet in Deng's reform, there is evidence of the recurrence of patrimonialism -- connecting the economic system to the government system. For example in 2014, Michal Forsythe, Chris Buckley and Jonathan Ansfield wrote: "Zhou Yongkang, a member of China's ruling Politburo Standing Committee from 2007 to 2012, is the subject of one of the highest-level corruption investigations in the history of the People's Republic of China. Several members of his family, over the years Mr. Zhou was in power, made investments in companies with ties to the China National Petroleum Corp., the state oil company formerly run by Mr. Zhou, although there is no evidence to show that Mr. Zhou was personally involved in the dealings." (Forsythe, Buckley and Ansfield, 2014) The pattern of 'families-of-high-government-officials-becoming-very-wealthy' had emerged in the economic reform in China.

Historically, the political dynamics of reform under Deng had oscillated from rapid reform to halting reform and to again rapid reform to halting reform again. Deng represented the liberal faction of the Chinese Politburo, while Chen Yun represented the conservative faction. Alternately, Deng pushed rapid reform, while Chen Yun pushed for halting reform: "This seesaw dynamic produced, in the terminology used by Chinese, alternate periods of 'loosening' (fang) and 'tightening' (shou)." (Lieberthal, 1995) But both Deng and Chen agreed that at no time should the Chinese Communist Party lose control of the government and country.

Thus the path to reform in China has been to liberalize the economy with increasing capitalism, while still having government remain a one-party authoritarian regime. In this mixed path of communism-capitalism, relatives of prominent government officials found opportunities to gain control of private companies and acquire wealth. Michal Forsythe, Chris Buckley and Jonathan Ansfield wrote: "The finances of the families of senior leaders are among the deepest and most politically delicate secrets in China. The party has for years followed a tacit rule that relatives of the elite could prosper from the country's economic opening, which rewarded loyalty and helped avert rifts in the leadership." (Forsythe, Buckley and Ansfield, 2014)

In the investigation begun about Zhou Yongkang, they wrote: "(Zhou's) son landed contracts to sell equipment to state oil fields and thousands of filling stations across China. His son's mother-in-law held stakes in pipelines and natural gas pumps from Sichuan Province in the west to the southern isle of Hainan. And his sister-in-law, working from one of Beijing's most prestigious office buildings, invested in mines, property, and energy projects. In thousands of pages of corporate documents describing these ventures, the name that never appears is his own: Zhou Yongkang, the formidable Chinese Communist Party leader who served as China's top security official and the de facto boss of its oil industry. But President Xi Jinping has targeted Mr. Zhou in an extraordinary corruption inquiry, a first for a Chinese party leader of Mr. Zhou's rank, and put his family's extensive business interests in the cross hairs." (Forsythe, Buckley and Ansfield, 2014)

In 2014, Xi Jinping was principle leader in the Chinese government, as General Secretary of the Communist Party of China, President of the People's Republic of China, and Chairman of the Central Military Commission. After all these years of the close ties between the government by senior communist officials and the economic development of 
their relatives, why did Xi decide to allow the investigation of Zhou Yongkang? Forsythe, Buckley and Ansfield suggested: "But another school of thought is that Mr. Xi considers the enormous agglomeration of wealth by spouses, children and siblings of top-ranking officials a threat to China's stability by encouraging mercenary corruption and harming the party's public standing. Those people say he has pushed the Zhou investigation beyond traditional bounds to signal that the rules have changed and that top leaders will be held responsible for their family's business activities, even though Mr. Xi's own family members have been among those who have grown rich. If that is so, the case has the potential to alter the political compact of China's boom years. For many elite clans, like Mr. Zhou's, acquiring stakes in lucrative enterprises that did business in the realm that the family patriarch supervised was not effectively banned - and sometimes not even well disguised." (Forsythe, Buckley and Ansfield, 2014)

The amount of wealth held by relatives was huge. Forsythe, Buckley and Ansfield wrote: "An investigation by The New York Times of the assets held by Mr. Zhou's relatives highlights the considerable sums involved and illustrates how deeply invested members of the party establishment are in industries where political connections are important. Three of Mr. Zhou's relatives - a sister-in-law, a son and Ms. Zhan, the son's mother-in-law - hold or have controlled stakes in at least 37 companies scattered across a dozen provinces, from Audi dealerships to property firms, according to corporate documents filed with the government. Seventeen focus on investments in energy, mostly in ventures with the state-owned oil giant China National Petroleum Corporation, which Mr. Zhou headed in the 1990s. Nine center on Sichuan Province, where Mr. Zhou served as party chief from 1999 to 2002 . . . In all, the holdings examined by The Times are worth at least one billion renminbi, or about $\$ 160$ million, though that estimate is based on a limited assessment of each company's value and does not include real estate or overseas assets, which are more difficult to identify and assess." (Forsythe, Buckley and Ansfield, 2014)

On can describe the occurrence of patrimonialism in modern Chinese society, using the graph theory connections of the societal systems model in Figure 6. The dotted arrows denote the important connections in the societal model to explain the empirical case of wealth accumulation by Chinese communist officials' families.

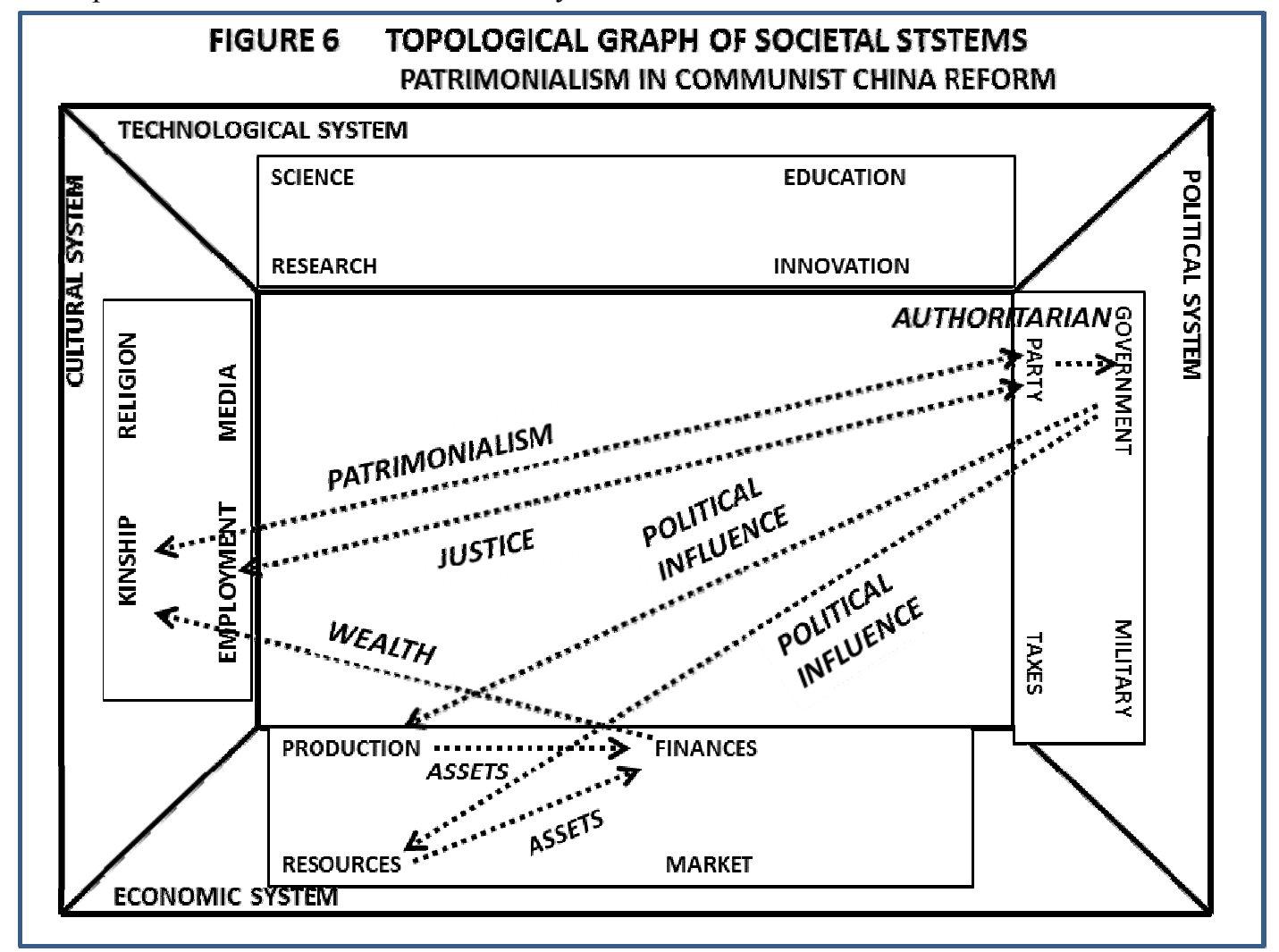

There is a connection between the party and the government, since the Chinese Communist Party controls the Chinese Government in an authoritarian fashion. Arrows of political influence denote how government officials can influence productive and resource assets in the economic system as financial gains by the kin of a government official. These financial gains appear as wealth connecting these family kin in the cultural plane to economic assets in the economic plane. And the line connecting kinship to the party, indicates the incident of patrimonialism occurring in the society. 
This pattern -- accumulating wealth through relatives while occupying major government posts - may have been widespread. Earlier in 2012, David Barboza had written about the then prime minister Wen Jiabao (who was about to retire): "The mother of China's prime minister, Wen Jiabo, was a schoolteacher in northern China. His father was ordered to tend pigs in one of Mao's political campaigns. And during childhood, 'my family was extremely poor,' the prime minister, Wen Jiabao, said in a speech last year. But now 90, the prime minister's mother, Yang Zhiyun, not only left poverty behind, she became outright rich, at least on paper, according to corporate and regulatory records. Just one investment in her name, in a large Chinese financial services company, had a value of $\$ 120$ million five years ago, the records show. The details of how Ms. Yang, a widow, accumulated such wealth are not known, or even if she was aware of the holdings in her name. But it happened after her son was elevated to China's ruling elite, first in 1998 as vice prime minister and then five years later as prime minister. Many relatives of Wen Jiabao, including his son, daughter, younger brother and brother-in-law, have become extraordinarily wealthy during his leadership, an investigation by The New York Times shows. A review of corporate and regulatory records indicates that the prime minister's relatives - some of whom, including his wife, have a knack for aggressive deal making have controlled assets worth at least $\$ 2.7$ billion." (Barboza, 2012)

While the pattern of wealth accumulation was apparently common, knowledge about it was not public. Barboza wrote: "In many cases, the names of the relatives have been hidden behind layers of partnerships and investment vehicles involving friends, work colleagues and business partners. Untangling their financial holdings provides an unusually detailed look at how politically connected people have profited from being at the intersection of government and business as state influence and private wealth converge in China's fast-growing economy. Unlike most new businesses in China, the family's ventures sometimes received financial backing from state-owned companies, including China Mobile, one of the country's biggest phone operators, the documents show. At other times, the ventures won support from some of Asia's richest tycoons. The Times found that Mr. Wen's relatives accumulated shares in banks, jewelers, tourist resorts, telecommunications companies and infrastructure projects, sometimes by using offshore entities. The holdings include a villa development project in Beijing; a tire factory in northern China; a company that helped build some of Beijing's Olympic stadiums, including the well-known 'Bird's Nest'; and Ping An Insurance, one of the world's biggest financial services companies." (Barboza, 2012)

Thus connections between the political, economic, and cultural planes is an example of the cultural-political pattern of 'patrimonialism'. The reason for the investigation into Zhou Yongkang's wealth was a worry by a new leader in the government that such extensive patrimonialism was undermining the Chinese peoples' perception of proper justice in the government of China by the Communist Party, distributing vastly unequal wealth through different employment opportunities.

What we see in graphing the connection of 'kinship' (in the cultural system of modern Chinese society) to the communist 'party' (of the authoritarian Chinese government) is a connection of 'patrimonialism', which has occurred throughout Chinese history. Graphing societal connections in this empirical historical example thus enables us to clearly identify a middle-range political theory called 'patrimonialism' For the stability or instability of political institutions, connections between the subsystems of the society are important to explain the stability of a society. The graphic analysis of this societal stasis indicates that the connections between societal sub-systems are principal contributors to societal stability or instability. This modern case of 'patrimonialism' has raised some worries about the stability of communist party control over contemporary China.

\section{Patrimonialism as a Middle-Range Societal Theory}

We are using this graphic form of societal systems as an analytical technique for providing evidence to the empirical grounding of 'middle-range' social science theories. In the discipline of the sociology, it has long been an American tradition that sociologists should seek 'middle-range' theory rather than 'grand' theory. This was particularly as espoused by Robert K. Merton. (Merton, 1967) Merton argued for this in order to establish sociological theory directly based upon empirical research. The middle-range societal theory being examined here is Francis Fukuyama's view of societal stability as a kind of systems 'balance', in which the principle of 'patrimonialism' has been an important factor in Chinese history. We will briefly review Fukuyama's middle-range political economy theory about this.

As have many political economists, Francis Fukuyama emphasized the importance of societal connections between politics, economy, and culture: "There is in fact a curious blindness to the importance of political institutions that has affected many people over the years, people who dream about a world in which we will somehow transcend politics. This particular fantasy is not the special province of either the Left or the Right; both have had their versions of it. The father of communism, Karl Marx, famously predicted the 'withering away of the state'. . . The fantasy of 
statelessness most prevalent on the Right is that the market economy will somehow make government unnecessary and irrelevant. Political institutions are necessary and cannot be taken for granted." (Fukuyama, 2011)

In the process of institutionalization of a government, Fukuyama had identified as a middle-range social theory, a universal opposition of tribalism to the state: "Virtually all peoples on earth owed primary obligations not to a state but to kinfolk; and they settled disputes not through courts but through a system of retributive justice; and they buried their dead on property held collectively by groups of kin." (Fukuyama, 2011) Fukuyama defined the problem of the modern state -- as institutionalizing power and justice in society beyond the cultural conditions of 'kinship'. The building of a 'state' extends the political system of a society beyond the boundaries of kin and tribes.

For a government of democracy, Fukuyama three identified three aspects that are essential to its institutionalization: authority, law, accountability. A successful democracy is one which has sufficient central authority as a 'state' to defend itself against external aggression, while also operating under a 'rule-of-law', and with 'accountability' for its actions (by the replacement of officials through periodic elections). The problem of constructing a 'good state' centers upon a proper balance between power and accountability. Fukuyama wrote: "Modern democracy was born when rulers acceded to formal rules limiting their power and subordinating their sovereignty to the will of the larger population as expressed through elections." (Fukuyama, 201)

For Fukuyama, the proper operation of a successful democracy centers (1) upon the 'rule-of-law', in which all citizens are treated equally under the law; and (2) upon 'accountability', in which offices are held by merit and not by kinship. But attaining an operational 'rule-of-law' and 'accountability' is neither easy nor historically stable. For example, Fukuyama wrote: "The story of how political institutions developed cannot be told without understanding the complementary process of political decay. Human institutions are 'sticky'; that is, they persist over time and are changed only with great difficulty. Institutions that are created to meet one set of conditions often survive even when those conditions change or disappear, and the failure to adapt appropriately, entails political decay. This applies to modern liberal democracies encompassing the state, rule-of-law, and accountability as much as to older political systems. . . . Moreover, the natural human propensity to favor family and friends -- something I refer to as 'patrimonialism' -- constantly reasserts itself in the absence of strong countervailing incentives. Organized groups -most often the rich and powerful -- entrench themselves over time and begin demanding privileges from the state." (Fukuyama, 2011)

The middle-range social theory of 'patrimonialism' is a cultural pattern that can reoccur in all societies, connecting culture to politics. The research in this paper is examining how a topological form of societal-system analysis can make more clear (highlight) the societal factor of 'patrimonialism' in the stability of Chinese society and in the evolution toward democracy in modern China.

\section{History: Patrimonialism in Ancient China}

We next use this societal systems model to further explore the extension of Fukuyama's political theory of 'patrimonialism' over time, from the present time back to the origin of the Chinese state. By extending the theory over time and societies, empirical validity for middle-range political theories can be established; and a societal systems topological model provides and efficient analytical methodology for accomplishing this temporal comparison.

Again we will draw upon Fukuyama's analysis of ancient China. Going back to the Zhou Dynasty in China's history, Fukuyama wrote: "China during the early Zhou Dynasty had evolved into something between a tribal and a chiefdom-level society. None of its units commonly referred to as 'states' in histories were true states. Zhou China was a textbook example of a patrimonial society. That is, the entire country was 'owned' by a series of local lords and their kin groups. Within the constraints of China's agnatic kinship rules, the land and the people living on it were patrimony or heritable property that was passed down to descendents. There was no distinction in this society between public and private; each ruling lineage raised armies, imposed taxes, and dispensed justice as it saw fit. All this, however, soon changed." (Fukuyama, 2011)

The change occurred from 770 BC to 256 BC, the time of the Eastern Zhou Dynasty. Fukuyama wrote: ". . genuine states began to coalesce in China. They established standing armies that were capable of enforcing rules throughout a defined territory; they created bureaucracies to collect taxes and administer laws; they mandated uniform weights and measures; and they created public infrastructure in the form of roads, canals, and irrigation systems. One state in particular, the kingdom of Qin, embarked on a remarkable modernizing project whose direct target was the kinship-based, patrimonial social order of the early Zhou" (Fukuyama, 2011) 
Fukuyama views several characteristics of a state as essential -- a standing army, enforcement of rules throughout a territory controlled by the army, bureaucracies to uniformly collect taxes and impose laws, the establishment uniform economic measures and regulations, and building a public infrastructure. Thus a systems model of a society -- which includes Military (standing army), Government (laws, regulation, infrastructure), Taxes (government finances) -- can depict Fukuyama's criteria for a state. Also the additional societal sub-system of Culture can depict Fukuyama's focus upon tribes, kinship, and patrimonial order. Accordingly, the Weberian societal systems model we are using to describe the stasis of a society is capable of encompassing the factors in Fukuyama's account of the history of states and their dynamics.

Toward the end of the Eastern Zhou Dynasty, seven feudal powers fought for control of territories in China, called the Seven Warring States. By 221 BC, Qin emerged dominant and temporarily unified China; and this unification would provide a continuing model of a unified empire throughout Chinese history, Figure 7.

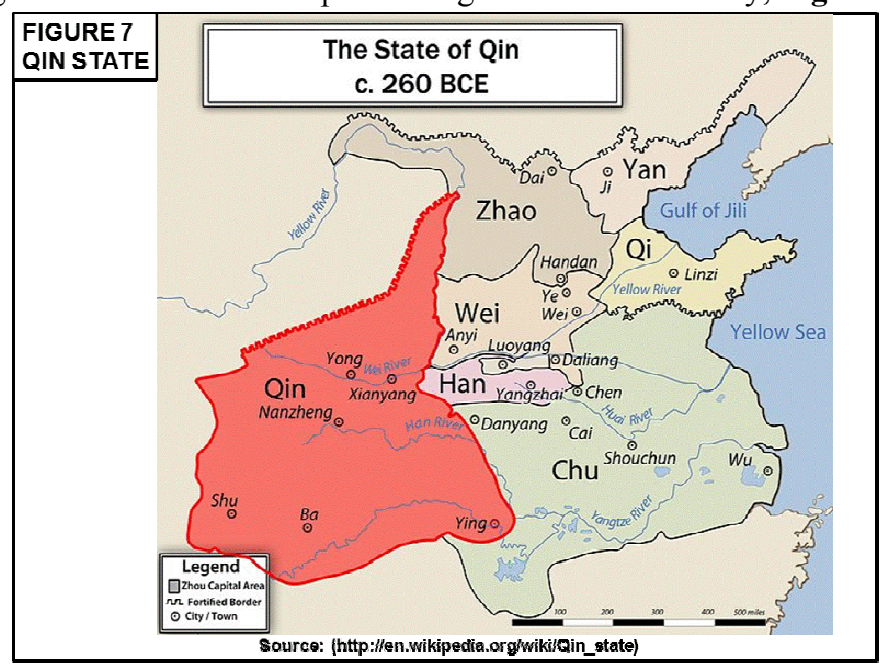

Fukuyama wrote: "Modern state institutions were gradually implemented all over China in the later years of the Zhou Dynasty, but nowhere more so than in the western state of Qin." (Fukuyama, 2011) The organization of the Qin state focused upon military capability, shifting in military technology from the use of chariots to large masses of infantry armed, with bows and pikes. To attain these masses of infantry, Qin mobilized its peasants, attaining up to $20 \%$ mobilization; and this can be compared to later European mobilization figures of population, at a level of only $1 \%$ (for example, in the Roman Empire). (Fukuyama, 2011)

To pay for the mobilization of conscripted armies, Qin taxed agricultural land based upon allotments of land to groups of peasant families. This kind of taxes and agricultural organization had begun earlier in $590 \mathrm{~B}$ in the state of $\mathrm{Lu}$. This systematic taxation of family groups decreased the power of kinship groups to control land.

Also Qin instituted a meritocratic administration. Fukuyama wrote: "It is safe to say the the Chinese invented modern bureaucracy, that is, a permanent administrative cadre selected on the basis of ability rather than kinship or patrimonial connection." (Fukuyama, 2011)

Also there were some advances in technology. There was a shift from bronze tools to iron tools. There was an improvement in how to yoke animals to plows. Thus both military and agricultural technology had some improvements. (Fukuyama, 2011)

Also there were changes in cultural were also occurring. Fukuyama wrote: "It is notable that the extremely violent centuries of (Chinese history called) the late Spring and Autumn and the Warring States era produced one of the greatest cultural outpourings in China's history. The extreme social dislocation created by perpetual wars occasioned considerable reflection on political and moral matters ... One of the many itinerant teachers attracting students in this period was Confucius ... The political significance of this intellectual ferment was twofold. First, it created something like an ideology, that is, a received set of ideas for the proper ordering of government by which later generations of Chinese could judge the performance of their political leaders. The best-known ideology was Confucian doctrine, but Confucianists engaged in bitter intellectual debates with other schools of thought, such as Legalism." (Fukuyama, 2011)

The end of the Warring States era occurred with the Qin conquests; so the first 'empire' in China was accomplished through conquest. And the new Qin dynasty saw the need to build a strong central state. Fukuyama wrote: "The Qin 
state builders saw clearly that the kinship networks of earlier ages were impediments to the accumulation of power, so they implemented policies deliberately intended to replace them with a system that tied individuals directly to the state." (Fukuyama, 2011) Shang Yang justified the centralization of power in the state as a new ideology, which later came to be known as 'Legalism'. Throughout the history of China, even down to the present, ideology about the state was in the form of an opposition between Legalism and Confucianism. Fukuyama wrote: "Confucianism is an intensely backward-looking doctrine that roots legitimacy (of the state) in ancient practices. . . Family and kinship were at the core of ... patrimonial order, and Confucianism can in many ways be seen as an ideology that builds a broad moral doctrine of the state outward from a model based on the family. . . This tension between the family and the state, and the moral legitimacy that Confucianism gives to family obligations over political ones, has persisted throughout Chinese history." (Fukuyama, 2011)

Thus the concept of a patrimonial political order can be seen as the basic societal 'structure-process' in a tribal organization of society. The construction of a state encompassing different tribes over different territories requires a central political order (state) opposed to patrimonial order (tribe). Fukuyama regarded the Chinese political thought of 'Legalism' of Shang Yang and Han Fei in the Qin state as justifying the control of an emperor over the people solely by the military power of the emperor -- over and above any patrimonial ties. In contrast at the time in China, there had been the earlier political thought of Confucius, who had constructed the idea of a state wherein ethical obligations bounded the emperor by familial ties. The emperor was thought of as a kind of greater father of the country, with an ethical obligation to protect and succor the greater family of China. This difference in political thought, between Chinese 'Legalism' and Chinese 'Confucianism', turned upon whether or not the political authority of the head of state (emperor) was justified solely by power (Legalism) for by patrimonial allegiance in a kinship-ordered state (Confucianism).

In Figure 8, we topologically graph the systems connections, for the description of the building of the Qin state. First, there was an Anti-Patrimonialism policy which focused power on the government as a centralized State, taking government offices away from Kinship relations. This was partly accomplished by using the educational sub-system to train competent administrators for the state as a meritocratic administration. This was also accomplished by fostering an ideology of Legalism and suppressing Confucianism. Second, there was a conscription of peasants for a bow \& pike-armed-infantry to create a large standing army -- conscripted army. Third, there was a reorganization of land and imposition of central state taxes upon agricultural production throughout China-- agricultural tax. Fourth, there were advances in technology in the introduction of iron tools and the yoking of animals and land and water management which increased agricultural production -- agricultural innovations.

FIGURE 8

TOPOLOGICAL GRAPH OF SOCIETAL SYSTEMS OF A CENTRALIZED STATE IN THE QIN DYNASTY

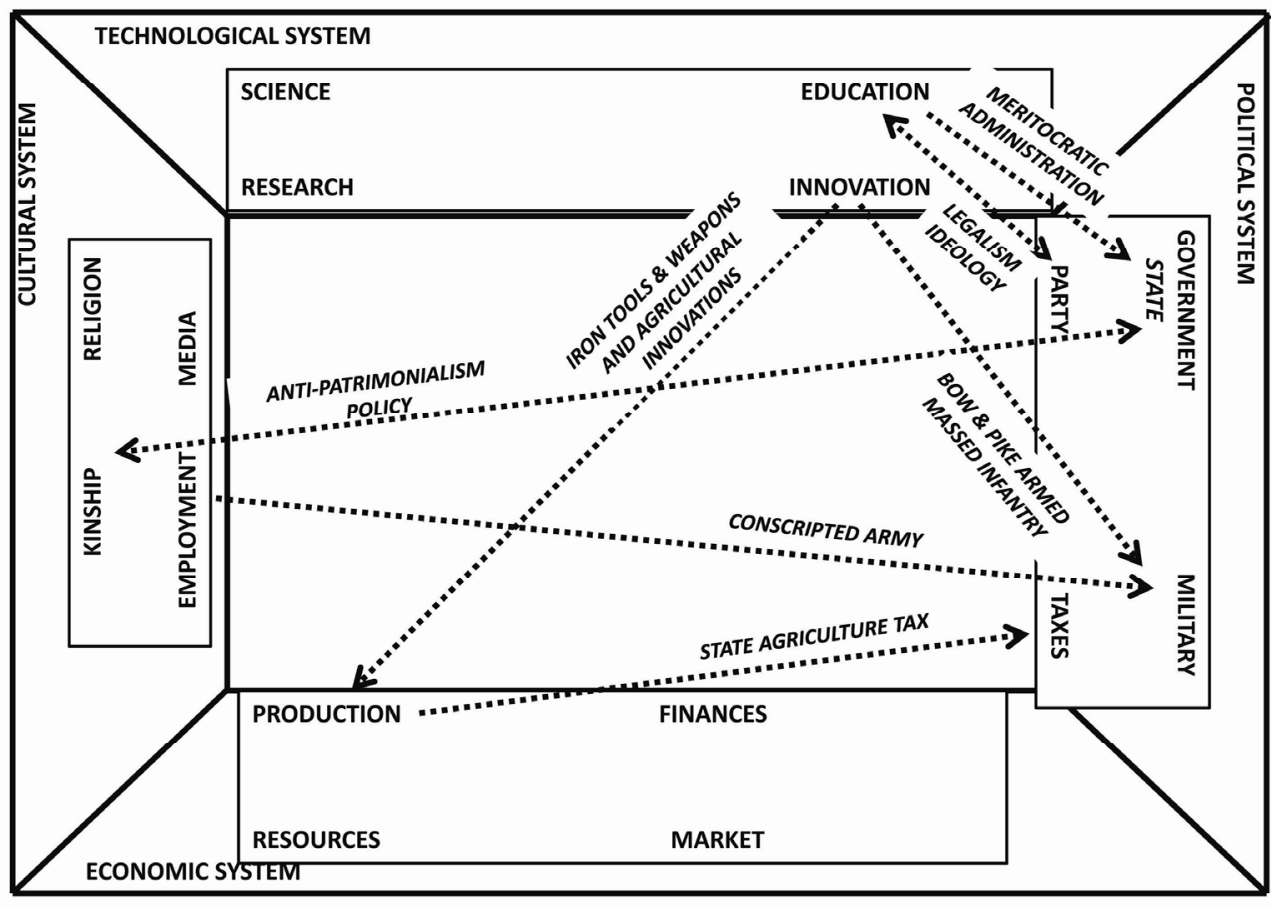


However, the Qin Empire did not last, collapsing after the death of its founder, (Figure 9). Fukuyama described: "The founder of the first unified Chinese state, Ying Zheng (also known by his posthumous temple name Qin Shi Huangdi) was an energetic megalomaniac who used political power to reshape Chinese society. The world-famous army of terra-cota warriors, unearthed in 1974, was created on his behalf and buried in a gigantic mausoleum. . Q Qin shi Huangdi extended the institutions of his native Qin to the whole of China and thereby created not just a state but what would become, under his Han Dynasty, successors, a unified Chinese elite culture." (Fukuyama, 2011)

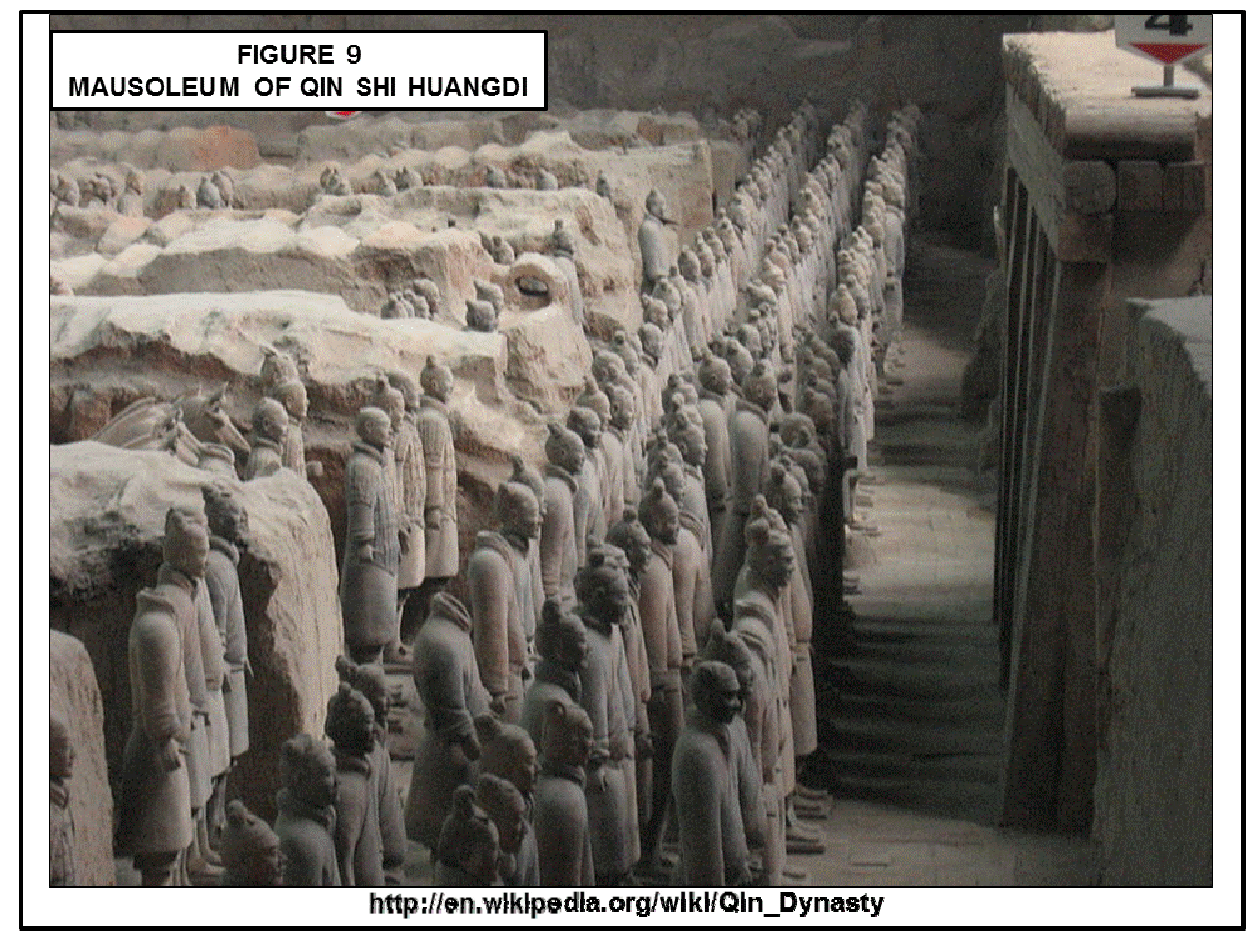

The Qin Emperor's institutionalization of his Legalistic state had been brutal. Officials trained in Confucian ideals resisted the change. The Emperor ordered the burning of classical books and had many resisting Confucian scholars buried alive. The Qin rule was harsh; and after the death of the Emperor, uprisings occurred all over China. An aristocrat, Xiang $\mathrm{Yu}$, raised a new army with the help of one of his followers, a peasant named Liu Bang. They marched upon the Qin capital and seized the government. Liu Bang's forces next turned against and (after four years of civil war) defeated Xiang Yu forces. In 202 BC, Liu Bang established a new dynasty later called the 'Earlier Han Dynasty' -- after the posthumous name of Liu Bang as Han Gaozu.

This new regime established by Han Gaozu endured four hundred years, from $202 \mathrm{BC}$ to 220 AD. Fukuyama wrote: "The initial Han equilibrium was based on a balance between the interests of all parties in creating a strong, unified central Chinese state to avoid the turmoil and warfare of the Eastern Zhou, and the interests of the local elites across China who wanted to hold onto as much of their power and privilege as possible." (Fukuyama, 2011) The new Han government balanced between the feudal organization of family ties and the state organization of force. Fukuyama wrote: "Gaozu created a two-track system. Part of the realm reverted to Zhou feudalism. . . The other part of the realm retained the impersonal comradery/prefecture structure of the Qin monarchy, which constituted the core of Gaozu's own power." (Fukuyama, 2011) We can topologically depict the Han Dynasty system as a combination of a centralized state and some feudal structure, as in Figure 10. 
FIGURE 10 TOPOLOGICAL GRAPH OF SOCIETAL SYSTEMS O F THE STATE IN THE HAN DYNASTY

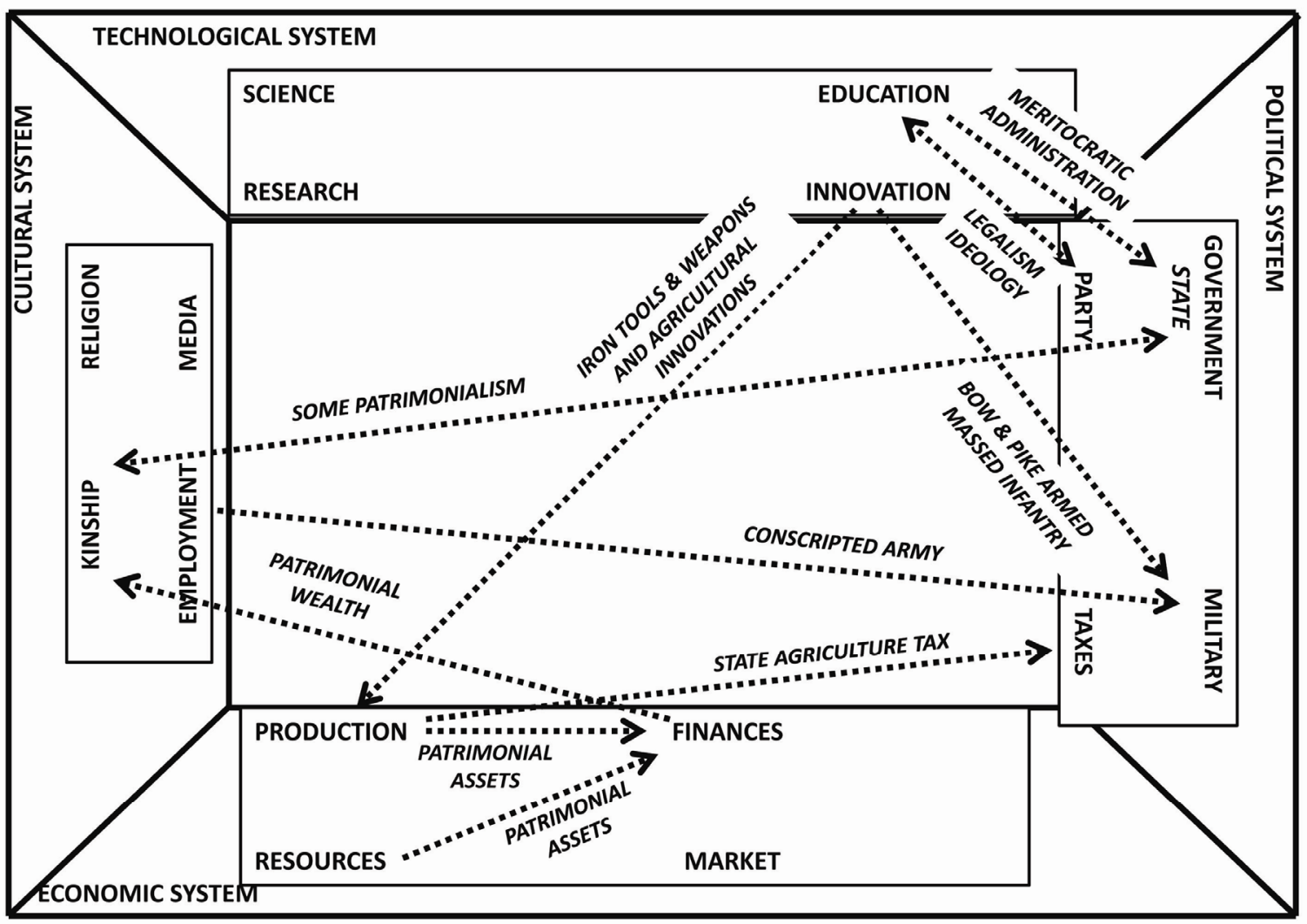

It is interesting the Fukuyama viewed stability within the Early Han Dynasty as a kind of political 'equilibrium' -balancing the interests of the different parties in the state. Thus political stasis in a society can be a kind of equilibrium between different-party interests.

\section{Results of the Research}

Societies are complicated social objects. The Weberian four-system model of a society helps address this complication by neatly dividing society's systems into four kinds: Cultural, Political, Economic, Technological. And a further fourfold division of each sector then creates a sixteen-unit functional model of a society. Sixteen sub-systems are many but still finite enough (1) to deal with complexity and (2) within which to analyze the functioning of a society as stasis (stable state). Moreover, this model is applicable to any society and over the times of its history. Societal histories are the empirical basis for constructing societal theory; and analytic models provide the analytic framework for comparing social science theory construction to empirical reality, to the natural experiments of any society -- its histories.

Stability or instability of a society is an important question. Sometimes societies become unstable because of events external to the society and sometimes because of events internal to the society. For example, instability of the Russian and German societies at the end of World War I were due to the external event of the war. In contrast, internal events (stock market collapse and subsequent bank runs) were the immediate factors to bring about the 1930s U.S. Great Depression. Also internal events of deregulation and financial fraud induced the instability of the U.S. financial system in 2007, the melting down of the U.S. economy. The study of societal instabilities is methodologically assisted by analyzing the historical events in the topological framework of societal dynamics theory. For example, the author used this methodology to analyze the Russian and German instabilities in (Betz, 2011), the U.S. Great Depression in (Betz, 2013), and the Global Financial Crisis (Betz, 2012).

A topological (graph theory) model of the four-fold Weberian system model of a society can identify all the logically-possible connections between the sub-systems -- as explanatory relations for understanding the stability/ instability of societal stasis. There are 120 such explanatory relations in the graphic system model. Of these, there are 
24 endogenous (inside) relationships within the four systems (cultural, economic, political, and technological systems). And there are an additional 96 explanatory relations connecting between (exogenous) the four systems. The one-hundred-twenty explanatory relations is a large number, but not an infinite number.

The importance of this methodological approach of societal dynamics is that it provides a structure-functional an framework for analysis of societies, in alterations of stasis and change. Societies are structural-functional objects, as long ago described by sociologists, such as Talcott Parsons. (Parsons, 1951). The topological analysis of 'societal dynamics' used in these cases is a graphical methodology for expressing both structure and function in a society, as composed of societal systems. (Betz, 2011)

Of course, societies are functional objects in nature and not mechanistic objects, such as physical things. In comparison in the physical/biological science, there is a mechanistic description of physical objects and, accordingly, only one kind of explanation - 'cause-effect' -- the cause of a force effecting change in the motion of a physical object. In contrast, since society is not a mechanistic thing but a functional object, there is no causality (causes) in societal explanation. Functional explanations are more complicated than a single mechanistic cause-effect explanation. For the social object of a society, one needs an observational framework, which is not the physical space-time framework of the mechanistic physical sciences. Instead, the observation of societies requires a societal perceptual space, consisting of the social-science dichotomies of individual-society, group-process, and action-reason. And in this perceptual space, a change-event of a society can be explained in 15 relations, Figure 11.

FIGURE 11 EXPLANATIONS IN A HISTORICAL SOCIETAL EVENT AS RELATIONSHIPS BETWEEN THE PRINCIPLE FACTORS

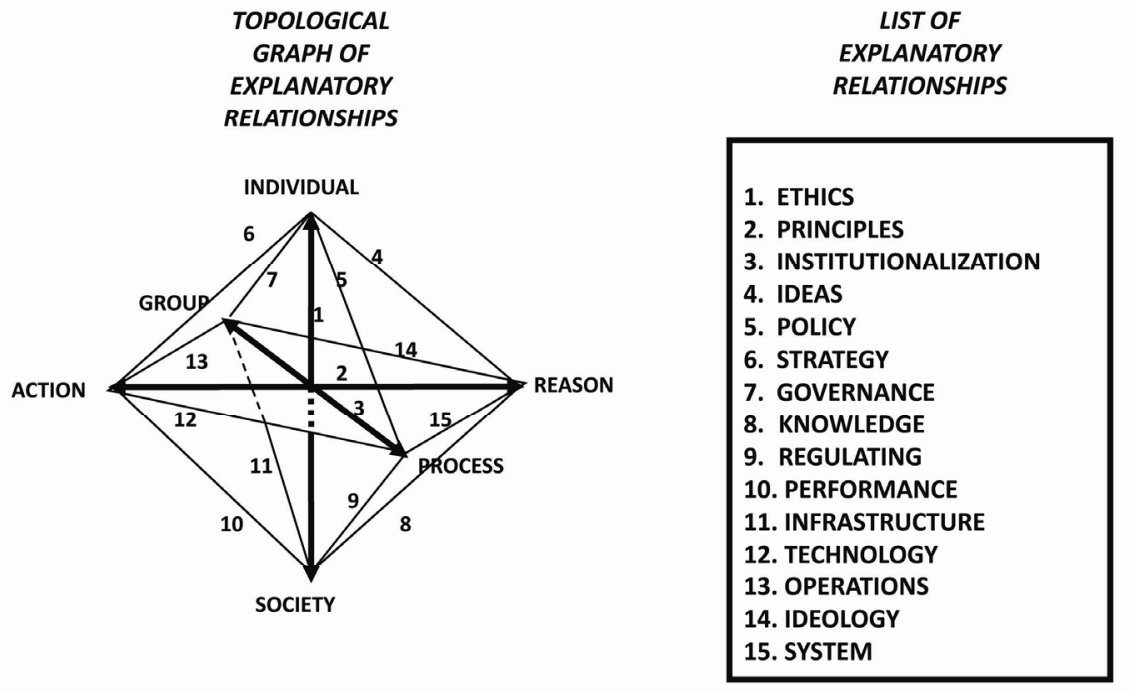

Change in a societal from a stable state (stasis) occurs as a crisis by a change event. After a change event, an altered societal structure can emerge as a new stasis. Thus the functional time of a society is not physical time, but a series of change events which alter stasis.

In analyzing change in a society, there are fifteen possible explanatory relations (societal explanations of change). In analyzing the stasis of systems in a society, there are one hundred twenty possible explanatory relations (societal explanations of stasis).

Explaining the history of societal events (change and stasis) is a more complicated analysis than explaining physical events.

In terms of future research, one can see that these topological models (of societal event-change and societal stasis) are yet qualitative models and not quantitative models. However, any topological graphic form can be translated into a matrix form. And in a matrix form, quantitative information about an explanatory relationship can be stored (expressed). Thus the qualitative topological models of societal dynamics can in the future be used quantitatively in matrix form -- as a template for quantitative information about the dynamics of societies. 


\section{Conclusion}

The added value of this research lies in continuing to extend topological-modeling of societies across the social science disciplines, as a cross-disciplinary analytical framework for historical cases. The methodology of topological modeling of societal systems and societal change provides a general framework for abstracting important factors and explanations in historical events, which can provide evidence for generalized patterns. These patterns are expressed as mid-range theories, which can occur in different societies and in different times. This methodology provides relevant and useful sets of explanations for explaining the complexity of historical cases -- 16 explanations for a societal change event and 120 for a societal systems stasis.

The limitation of the research is that no one historical case (nor even several historical cases) can 'prove' the validity of a middle-range social theory -- since abstraction from empirical evidence is logically an inductive process. But these can provide substantive evidence to take a theory seriously. And this is an important and fundamental aspect of methodological nature of all the social sciences - basing societal theory upon societal histories.

As there is no 'causality' in social science explanation, hence there can be no 'prediction' of social change. But there are other kinds of explanations methodologically appropriate to structural-functional social science. Two of these are 'prescriptions and 'themes', which can be used in middle-range theorizing. These can clarify the complications of history (and particularly the complications of current history). In the cases examined here we have seen evidence for such a prescriptive theory. This prescriptive theory is by Francis Fukuyma. It is to restrict having too much of a family-oriented culture carried over into the economic-political structures of a society, as 'patrimonialism' contributes to the instability of a 'state' form of societal governance.

\section{References}

Barboza, David. (2012). Billions in Hidden Riches for Family of Chinese Leader, New York Times. October 25. http://www.nytimes.com/2012/10/26/business/global/family-of-wen-jiabao-holds-a-hidden-fortune-in-china.htm 1

Betz, Frederick. (2001). Executive Strategy, (New York: John Wiley, 2001) ISBN 0-471-38402-X

Betz, Frederick. (2011). Societal Dynamics (New York, Springer) ISBN 978-1-4614-1278-6.

Betz, Frederick. (2012). Control in Knowledge Economies, Journal of Knowledge Economy. http://dx.doi.org/10.1007/s13132-012-0100-0

Betz, Frederick. (2013). U.S. Economics Holy Grail - The Great Depression. Business and Management Research. Vol 2. No. 1.

Forsythe, Michael, Chris Buckley \& Jonathan Ansfield. (2014). Investigating Family's Wealth, China's Leader Signals a Change, New $\quad$ York 19. http:/www.nytimes.com/2014/04/20/world/asia/severing-a-familys-ties-chinas-president-signals-a-change.html ?hp\&_r $=0$

Fukuyama, Francis. (2011). The Origins of Political Order. Farrar, Straus and Giroux.

Merton, Robert. (1967). Social Theory and Social Structure. Free Press.

Parsons, Talcott. (1951). The Structure of Social Action. Free Press. 1967 edition.

Weber, Max. (1958). From Max Weber: Essays in Sociology (Translated by H. H. Gerth and C. Wright Mills) Galaxy Book. 